\title{
Considerations for ceramic inlays in posterior teeth: a review
}

This article was published in the following Dove Press journal:

Clinical, Cosmetic and Investigational Dentistry

17 April 2013

Number of times this article has been viewed

\author{
Christa D Hopp' \\ Martin F Land ${ }^{2}$ \\ 'Section of Operative Dentistry, \\ ${ }^{2}$ Section of Fixed Prosthodontics, \\ Southern Illinois University, \\ Alton, IL, USA
}

Correspondence: Christa D Hopp Section of Operative Dentistry, School of Dental Medicine, Southern Illinois University, 2800 College Avenue Building 284, Alton, IL 62002, USA

$\mathrm{Tel}+\mathrm{I} 6184747056$

Fax + I 618474714 I

Email chopp@siue.edu
Abstract: This review of ceramic inlays in posterior teeth includes a review of the history of ceramic restorations, followed by common indications and contraindications for their use. A discussion on the potential for tooth wear is followed by a review of recommended preparation design considerations, fabrication methods, and material choices. Despite the improved materials available for fabrication of porcelain inlays, fracture remains a primary mode of inlay failure. Therefore, a brief discussion on strengthening methods for ceramics is included. The review concludes with a section on luting considerations, and offers the clinician specific recommendations for luting procedures. In conclusion, inlay success rates and longevity, as reported in the literature, are summarized.

Keywords: inlays, ceramic, posterior, review, $\mathrm{CAD} / \mathrm{CAM}$, leucite reinforced, lithium disilicate, longevity, esthetics, luting, wear, stress, selection

\section{Introduction}

Ceramic inlays offer an aesthetic alternative to metal class I or II restorations. Their primary use is in compromised posterior teeth with intact buccal and lingual walls. These restorations offer the opportunity to conserve tooth structure while taking advantage of the mechanical benefits of modern adhesive technology, which can strengthen the compromised tooth. Ceramic inlays offer a viable alternative to amalgam or castgold restorations, both of which have enjoyed long histories of clinical success.

Amalgam restorations have proven to be fairly forgiving when excellent isolation is problematic, in contrast to the demands of adhesive bonding. Achieving proximal contact in an amalgam restoration is straightforward because the material is condensable, and the material has a proven history of clinical longevity. Microleakage of amalgam restorations may be reduced through the use of bonding ${ }^{1}$ while potentially reducing postoperative sensitivity, pulpal inflammation, and the incidence of recurrent caries. ${ }^{2}$ However, its unnatural appearance remains a disadvantage. Further, environmental concerns about mercury and amalgam discharge have resulted in increased externally imposed controls that focus on potential pollution. ${ }^{3-5}$

Cast-gold inlays are the benchmark to which alternative restorations must be compared. The longevity of a well-made gold inlay remains second to none: they are extremely durable and strong, result in minimal wear on antagonists, and in contrast to amalgam, the material is not susceptible to corrosion. Gold inlays remain a viable restoration when superior strength is required, as for instance in high-load locations in the dental arch, such as second molars. When appearance is of little concern to the patient, gold remains a predictable choice, especially for larger restorations. 
Ceramic inlays, by contrast, allow the practitioner to achieve an excellent shade match with surrounding natural tooth structure. Provided that the appropriate shade is selected and the restoration is fabricated with proper translucency, ceramic inlays can be almost indistinguishable from the tooth being restored. They have improved physical properties in comparison to direct posterior composite resin restorations, and when preparation margins are situated in enamel, ceramic inlays offer the potential of reduced microleakage by comparison to either amalgam or gold. However, the current adhesive systems have not completely eliminated microleakage when cervical margins are located in dentin. ${ }^{6}$

\section{History}

Ceramic materials were first used in dentistry to fabricate porcelain denture teeth in the late $1700 \mathrm{~s},{ }^{7}$ but another century would pass before Charles H Land, a dentist from Detroit, MI, USA, would fabricate the first ceramic crown. His process relied on providing support for a ceramic paste during firing with a thin platinum foil adapted to the die to minimize slumping of the porcelain mass. Land was granted a patent for his extracoronal restoration technique in $1887 .^{8}$ The feldspathic porcelains he used were soon applied to the fabrication of intracoronal restorations, and a number of techniques for the fabrication of porcelain inlays were reported in subsequent years. These also relied on the use of a foil to support the porcelain mass during sintering. A number of sequential firings were typically recommended: initially in gasoline-powered furnaces and eventually in electric ovens. ${ }^{9}$

When resin polymers were introduced in dentistry in the 1940 s, ceramic inlays lost some popularity until the limitations of composite-resin restorations became apparent. Specifically, wear, discoloration, and marginal leakage limited the longevity of the early composite-resin restorations. ${ }^{10}$

With the advent of metal-ceramic restorations, leucite containing porcelain frits came into being, which exhibited increased coefficients of thermal expansion necessary to permit bonding to newly formulated gold alloys. ${ }^{11}$ Several years later, McLean and Hughes suggested the incorporation of alumina to significantly strengthen the brittle ceramic. ${ }^{12}$

Early ceramic restorations suffered in terms of their aesthetic appearance, due to air firing that resulted in significant porosity, causing a grayish appearance of the completed restoration. Once vacuum firing was introduced, ${ }^{13}$ denser restorations could be fabricated with a more translucent and aesthetically pleasing appearance. ${ }^{14}$

The early dental porcelains had limited applications in posterior locations because of the relatively low strength of the feldspathic ceramic, and fracture was a common complication. Over time, this prompted the development of higher-strength ceramics. In the early 1970s, Duret pioneered the use of computer-aided design/manufacturing (CAD/CAM) in dentistry. ${ }^{15}$ Approximately 10 years later, Mörmann et al developed the first chair-side economical restoration of aesthetic ceramics (CEREC) system, which allowed inlays to be machined from prefired ceramic blocks in the dental office. ${ }^{15-18}$ The resulting restorations had less than optimal adaptation, and required considerable intraoral occlusal reshaping. In the early 1980s, the concept of acidetching porcelain to permit use of resin composite for luting porcelain restorations ${ }^{19}$ was developed. At about the same time, castable glass ceramics were introduced. ${ }^{20,21}$ Shrinkfree ceramics were introduced ${ }^{22}$ more or less concurrently with Sadoun's development of glass infiltration of alumina (In-Ceram). A few years later, Dong et al introduced pressed glass-ceramic restorations (Empress). ${ }^{23}$

Today, material choices for posterior ceramic inlays include use of a higher-strength ceramic material, or alternatively a high-strength ceramic core material may be veneered with a more translucent aesthetic veneer. ${ }^{24}$ The latter approach has lost some popularity, but may enjoy renewed interest, as the clinical application of opaque zirconium restorations is becoming more prevalent due to their superior strength. Manufacturers are continuing to develop and improve the combination of acceptable strength and aesthetics through translucent lithium disilicate and zirconia materials.

\section{Use of ceramic inlays}

Ceramic inlay indications include most of the typical indications for cast-metal inlays, with the added requirement for a tooth-colored restoration. Ceramic inlays can be conservative of tooth structure, and permit preservation of much coronal tissue. They can be used in lieu of a metal-casting or amalgam restoration in patients who require a class II restoration where buccal and lingual walls remain intact, and offer a viable alternative where excessive isthmus width may preclude the use of a direct posterior composite restoration. Ceramic inlays are stronger than direct posterior composite resins, offering superior physical properties than the latter, as the limited degree of polymerization conversion of direct posterior composites limits their strength. ${ }^{25}$ However, the advantage of the ceramic inlay over the composite resin may be limited by the possible need for an additional appointment, the greater skill level required to deliver the treatment, and the higher cost associated with the materials used. 
Contraindications for ceramic inlays exist in dentitions of patients with poor plaque control or active decay. Since porcelain fracture has been reported as a primary reason for ceramic inlay failure, heavy loading should be avoided. ${ }^{26}$ Under those circumstances, the brittle nature of the ceramic makes these restorations a higher risk. In the presence of an unfavorable occlusion, a group-function occlusal arrangement, or in patients exhibiting evidence of parafunctional activity such as bruxism or clenching, prudence is advised.

Consideration should be given to alternative restorations when faced with the inability to maintain a dry field precluding proper luting procedures. Accordingly, preparations with deep cervical subgingival extensions, and other clinical situations where excellent isolation is problematic, may constitute a contraindication.

\section{Wear}

Restoration wear, frequently seen with posterior composite resins, is generally not a clinical concern with ceramic inlays, while the latter offer comparable or even improved aesthetics.

Challenges with ceramic restorations include difficulties encountered in the development of precise occlusal contact. Often, it is most practical to bond the restoration in place prior to final verification of the occlusion, which in turn can result in a compromised finish and more irregular surface finishes on the ceramic restorations than can be achieved when they are polished in the dental laboratory. Although intuitively, increased surface roughness might appear to be associated with increased wear, in vitro enamel wear does not appear to be affected by porcelain-surface roughness, ${ }^{27,28}$ presumably because the ceramic material fairly rapidly adopts a "polished" surface after initial sliding contact. Yet empirically, porcelain restorations have been shown often to be associated with significant enamel wear over time. Such wear may result from sliding contact between the natural tooth and the ceramic restoration. The use of lower-fusing porcelains has been shown to reduce enamel wear in vitro, which appears to correlate well with clinical reports, ${ }^{29-31}$ although comparable wear between low-fusing porcelains and classic feldspathic porcelain has been reported as well. ${ }^{32}$

However, it remains difficult to correlate in vitro laboratory tests to clinical outcomes. Ceramic microstructure, fracture toughness and hardness all have been implicated in resulting enamel wear. ${ }^{33,34}$ Abrasive surface features may develop on a ceramic surface during function and impact resulting wear. ${ }^{35}$
Despite the contradictory nature of many wear studies, many clinicians developed an interest in polishing ceramic surfaces as opposed to glazing. In part, this logically flows from practical considerations in practice; in particular, the improved control by the clinician over surface texture and luster, leading to improved aesthetic results. Well-polished ceramic surfaces can equal or surpass the strength of glazed, fired porcelain, ${ }^{36,37}$ and have been shown to be smoother than autoglazed, fired ceramic surfaces. ${ }^{38}$

\section{Ceramic inlays as retainers}

Inlays typically exhibit lower retention values compared to full-veneer crowns, limiting their application as retainers for fixed partial dentures subjected to higher loads and as retainers for fixed dental prostheses (FDPs) replacing multiple teeth. A number of authors have recently reported on the potential of zirconium inlays as conservative retainers for short-span FDPs. ${ }^{39-41}$ In some of these efforts, zirconia substructures are designed to be veneered with a pressed ceramic overlay, enabling adhesive luting procedures.

Multiple studies have analyzed stress distributions of such FDPs using finite-element analysis. ${ }^{42,43}$ Such studies suggest that peak stresses in inlay-retained FDPs are approximately $20 \%$ higher than in FDPs supported by complete coverage retainers. One study of layered zirconia and porcelain found substantially higher moduli of rupture in comparison to other layered all-ceramic systems. ${ }^{44}$ How such will translate into long-term clinical performance is not well understood and will require longer-term clinical follow-up evaluations.

\section{Preparation design}

Preparation design is influenced by the selected restorative material (weaker materials requiring additional bulk), the fabrication method, and the ability to bond the restoration. Clinicians must further consider aesthetics, fracture resistance, and edge-strength capabilities of the selected restorative material. The potential advantages of enamel bonding versus dentin bonding should also be taken into consideration, as well as the variance in bonding to different qualities of dentin and the possibility of limited retentive form.

Ceramics are brittle. Though significant progress has been made in the development of new and improved materials, the inherent brittleness remains a limiting factor that can be minimized through proper preparation design.

Preparation guidelines for ceramic inlays differ from those for cast gold (Table 1). Retention form is not as critical due to the bonded nature of the restoration, and bevels are contraindicated. Cavosurface angles of $90^{\circ}$ are 
Table I Preparation guidelines for monolithic ceramic restorations

\begin{tabular}{ll}
\hline Internal form & External form \\
\hline 1.5 to $2 \mathrm{~mm}$ of pulpal depth & $\begin{array}{l}90 \text { degree cavosurface } \\
\text { margins }\end{array}$ \\
$\begin{array}{l}\text { Rounded internal line angles } \\
2 \mathrm{~mm} \text { of isthmus width } \\
10 \text { to } 12 \text { degrees of axial wall }\end{array}$ & $2 \mathrm{~mm}$ of occlusal reduction \\
convergence & for cuspal coverage \\
Greater than or equal to 10 degrees & Smooth flowing margins \\
of divergence on buccal and lingual walls & \\
I to $1.5 \mathrm{~mm}$ of axial wall reduction & \\
\hline
\end{tabular}

preferred, and the preparation must have smooth-flowing margins to facilitate the fabrication of the restoration. Rounded internal line angles and the butt-joint cavosurface margins facilitate many aspects of conventional laboratory or chair-side inlay fabrication. The bulk of ceramic must be established in areas of potential contact from adjacent and opposing teeth, and good visual access to all prepared surfaces facilitates optical capture and subsequent fabrication. ${ }^{45,46}$

Undercuts should be avoided. A minimum cervicoocclusal axial wall convergence of $10^{\circ}-12^{\circ}$ is consistent with general recommendations for cast-inlay preparations, although the adhesive nature of the bond may permit deviation from that specific angle of occlusal divergence. Box walls should diverge in an occlusal direction by approximately $10^{\circ}$ or more, which will facilitate optical capture and reduce the risk of excessive binding during seating for initial evaluation. Often, it is not necessary to remove all undercuts once the desired outline form has been established, as it may be possible to simply block those out. Alternatively, such areas will not be captured by certain optical impression techniques, simply resolving the classic challenge of having to block out undercuts on die systems in the dental laboratory.

There appears to be a reasonable consensus about minimally required dimensions for all ceramic posterior inlay preparations. Generally, a minimum of $1.5-2 \mathrm{~mm}$ of pulpal floor depth, $1-1.5 \mathrm{~mm}$ of axial reduction, and $2 \mathrm{~mm}$ of isthmus width define minimally adequate preparation dimensions. Such isthmus width minimizes fracture risk by stresses resulting from occlusal forces. ${ }^{47}$ Insufficient material thickness will result in fracture. ${ }^{47,48}$ Without adequate reduction, isthmus width, and smooth $90^{\circ}$ cavosurface margins, the ceramic material will not be able to withstand the significant loads to which it is subjected posteriorly. ${ }^{49}$

Inlay preparations may be modified in part to overlay a compromised or weakened cusp. If in that manner a cusp is to be overlaid, occlusal reduction of at least $2 \mathrm{~mm}$ is recommended to allow sufficient occlusal ceramic thickness to predictably withstand occlusal forces without fracture. ${ }^{47}$

In a pulpal direction, axial reduction in proximal boxes should be a minimum of 1-1.5 mm deep. Such allows for conservation of tooth structure and the reduced need for bulk of ceramic due to a lack of direct occlusal forces while considering the minimal bulk needed to create a $90^{\circ}$ cavosurface margin.

The minimum dimensions cited above are suggested for commonly used ceramics, such as leucite-reinforced porcelain or lithium disilicates. If monolithic materials such as zirconium are used, these dimensions can likely be reduced, at least theoretically, and margin design altered due to the inherently greater material strength. At this time, long-term clinical performance data is limited, rendering this somewhat of an empirical matter. Further investigation appears warranted.

Depending on the amount of residual tooth structure after caries removal, it may be desirable to use a base material under ceramic inlays. Composite resin has adequate strength and rigidity to serve as a base material, whereas glass ionomer, with its lower modulus of elasticity, is too flexible, which may increase the risk of inlay fracture..$^{50,51}$

The informed practitioner, who has a clear understanding of applicable limitations, will be able to design clinical preparations that will result in posterior ceramic inlays with a predictable long-term prognosis. ${ }^{48}$

\section{Fabrication methods}

Ceramic inlays can be manufactured indirectly in the dental laboratory or in the dental office using chair-side CAD/CAM systems. Options for laboratory fabrication include firing dental porcelain on either a foil or a refractory die system, use of a pressed glass ceramic with a lost-wax technique, castable ceramics, or the restoration can be milled from prefabricated ceramic blocks in the dental laboratory or in the dental office. Different materials utilize the various fabrication methods and therefore result in distinct degrees of aesthetic quality and strength (Table 2). The lost-wax technique for ceramic restorations shares many preparation requirements with inlay preparations for cast metal: clearly defined margins, adequate clearance from adjacent teeth, and diverging walls. Of the multiple options for fabricating a ceramic inlay, only the prefabricated ceramic blocks can be used to manufacture the restoration chair-side through the use of a CAD/CAM milling unit. ${ }^{52}$

When using the milling process, an additional consideration is the limitation imposed by the geometry of the 
Table 2 Esthetics and strengths associated with material and method of fabrication

\begin{tabular}{|c|c|c|c|}
\hline $\begin{array}{l}\text { Restorative } \\
\text { material }\end{array}$ & $\begin{array}{l}\text { Fabrication } \\
\text { method }\end{array}$ & Esthetics & Strength \\
\hline $\begin{array}{l}\text { Feldspathic } \\
\text { porcelain }\end{array}$ & $\begin{array}{l}\text { Fired on } \\
\text { refractory die }\end{array}$ & Excellent & Weak \\
\hline \multirow[t]{2}{*}{$\begin{array}{l}\text { Leucite } \\
\text { reinforced }\end{array}$} & $\begin{array}{l}\text { Lost wax-pressed } \\
\text { ceramic }\end{array}$ & Excellent & Moderate \\
\hline & Milled ceramic block & Excellent & Moderate \\
\hline $\begin{array}{l}\text { Aluminous } \\
\text { core }\end{array}$ & $\begin{array}{l}\text { Slip cast; glass } \\
\text { infiltrated }\end{array}$ & Good & $\begin{array}{l}\text { Strong core; } \\
\text { weak veneer }\end{array}$ \\
\hline \multirow[t]{2}{*}{$\begin{array}{l}\text { Lithium } \\
\text { disilicate }\end{array}$} & $\begin{array}{l}\text { Lost wax-pressed } \\
\text { ceramic }\end{array}$ & Moderate & Strong \\
\hline & Milled ceramic block & Moderate & Strong \\
\hline
\end{tabular}

milling burs. Specifically, the width and length of the burs dictate the need for a flowing outline form. If a preparation outline contains any sharp angles, the diameter of the milling bur may prevent exact replication of the desired shape. This can then result in a restoration that will not seat fully, is overmilled, and/or may exhibit open margins. The length of the milling bur may also limit the ability to fabricate restorations with substantial occlusal gingival height, as might be the case in patients with moderate bone loss, where it is necessary to extend the preparation farther apically onto the root surface that is being incorporated in the preparation. This limitation can occasionally be overcome by increasing the angle of convergence of the preparation, although this is less conservative of tooth structure and may result in reduced retentive form. The exact degree of ideal divergence for the walls has been a subject of debate. ${ }^{53}$ Rounded internal line angles are advised for both pressed and milled ceramic. ${ }^{54}$ In the case of pressed ceramic, the rounded internal form allows for better flow of the ceramic material and less risk of binding and potential fracture of the restoration upon seating. In the case of milled ceramic, the rounded internal form is again required due to the shape of the burs milling the ceramic, and thus is also needed to achieve optimal adaptation.

An additional consideration is the nature of the bonding surface. The evolution of bonding systems and their chemistry is complex, and it is often difficult to simplify for direct practical clinical application. Generally, the bond to enamel is more predictable to achieve and stronger over time than the bond to dentin. ${ }^{55}$ Keeping this in mind during tooth preparation can improve the quality of the resulting adhesive bond. This can pose a challenging paradigm shift for clinicians who have been taught foundational concepts that focused on retention and resistance form. Enamel preservation often requires less tooth reduction and results in preparations that by classical standards would be considered to have minimal, little, or no retentive form. Once the occlusal outline form has been established, restoration retention may be solely dependent on the bond between the ceramic and tooth structure. Finding the ideal compromise between ensuring an optimal bonding surface and the best retentive form can be a clinical challenge, while posing a complex scientific challenge to researchers, as the number of variables is significant.

\section{Material selection}

Ceramic inlays can be fabricated from a number of materials, each of which has unique advantages and disadvantages. Current choices include feldspathic porcelains, leucitereinforced, lithium disilicates, and glass-infiltrated ceramics (Table 3). A limiting property of feldspathic ceramics is their inherent weakness in comparison to alternative material choices.

Glass-infiltrated ceramics (such as In-Ceram) consist of aluminous cores that are fabricated from an aluminous slip (an aqueous suspension of ceramic particles with dispersing agents) that is applied to a refractory die. The porous die absorbs the moisture, leading to porcelain condensation. After firing, glass infiltration is achieved as molten glass is drawn into the porous, fired slip through capillary action at high temperature. ${ }^{56}$ Veneering porcelain can then be applied to achieve the desired appearance and degree of translucency. The resulting restorations have less porosity and defects in comparison to conventional ceramics, with significantly improved strength that can be as high as 3-4 times that of traditional alumina cores. Magnesium- and zirconium-based In-Ceram materials are also available. Reports on marginal adaptation are varied,,$^{57}$ although several authors report good ${ }^{58}$ to very $\operatorname{good}^{59}$ marginal adaptation.

Heat-pressed ceramics can be leucite- or lithium silicatebased. The former can be used for the fabrication of ceramic

Table 3 Types of ceramic based on materials and manufacturer

\begin{tabular}{lc}
\hline Silica based & Non-silica based \\
\hline Feldspathics & Glass infiltrated Zr, Alum; Spinell \\
Multiple & InCeram (Vita/Vident) \\
Leucite reinforced porcelain & WolCeram (Vita) \\
Empress (ivocalar) & Densely sintered Al203 \\
eMax empress (ivoclar) & Procera (Nobel Biocare) \\
OPC (pentron) & Densely sintered ZrO \\
Finesse (dentsply) & eMax ZirCAD (ivoclar) \\
Lithium disilicate glass-ceramic & CEREC (sirona) \\
Empress 2 (ivoclar) & Cercon (dentsply) \\
G3 (pentron) & Lava (3M/ESPE) \\
eMax CAD (ivoclar) & \\
\hline
\end{tabular}


inlays, whereas the latter is primarily indicated for the fabrication of crowns and short-span anterior FDPs. Inlays fabricated from heat-pressed ceramics tend to exhibit excellent marginal adaptation, and good fracture resistance.

Lithium disilicate machinable blocks are available in a range of shades and translucencies. Lithium disilicate inlays exhibit excellent strength and appearance. The ability to have the material manufactured in a controlled block format lends itself to improved quality control and consistency that is less predictable with other methods.

In comparison to the classic cast inlay, the initial marginal adaptation of CAD/CAM restorations (CEREC) was rather poor ${ }^{60}$ but has improved with recent advances. ${ }^{61}$ Marginal and internal gap size can influence longevity and wear, discoloration, leakage, degradation of the luting agent, and the ability of the restoration to withstand loading. A comparison between pressed and milled inlay and onlay gap widths shows minimal differences after luting, ranging from 136 to 278 microns. ${ }^{62}$ Although milling procedures continue to improve, the challenge of overmilling is widely recognized. The relatively large internal gap, however, may allow these restorations to seat further, effectively reducing the marginal gap widths.

Microleakage has been studied in vitro with dye-penetration methods, and is typically less at margins in enamel than for margins located at the dentin-cementum interface. ${ }^{63,64}$ One study reports less dye penetration at dentinal margins when a highly viscous cement was used as opposed to a lowerviscosity resin luting agent. ${ }^{65}$ The clinical significance of the larger marginal and internal gap width will require long-term clinical studies.

\section{Strengthening of ceramics}

All ceramics contain fabrication defects and surface cracks, from which fracture can initiate. Porosity in dental ceramics is an inherent by-product of the condensation procedures used during fabrication. Clinically failed glass-ceramic restorations have been shown to initiate fracture from internal porosities. ${ }^{66}$ Leucite (potassium aluminosilicate) raises the coefficient of thermal expansion of dental porcelain, and results in increased hardness. ${ }^{67}$ Leucite-strengthened ceramics develop microcracks during the cooling phase, caused by the deliberate mismatch in coefficients of thermal expansion between the leucite crystals and the surrounding glassy matrix. ${ }^{68}$

The increased demand for stronger materials spurred the search for new materials and methods to strengthening existing glass ceramics. Strengthening methods for improved performance of dental ceramics include thermal tempering, chemical strengthening, crystalline reinforcement, and stressinduced transformation. Thermal tempering can result in compressive stress profiles that extend deeper than chemically derived stresses, but may have limited dental applications because cooling rates are difficult to control for objects that have complex shapes. ${ }^{69}$

Chemical strengthening relies on the development of a compressive layer at the ceramic surface, and can be effected by ion exchange. A relatively low-temperature firing of a ceramic coated with alkali salts results in exchange of smaller ions in the ceramic material, with larger ions resulting in a surface layer in a state of compression. Such ion-exchange strengthening has been shown to increase flexural strength of feldspathic porcelains by as much as $80 \%{ }^{70}$ This is somewhat similar to the compression that results from application of a separately fired surface glaze where a comparatively low-expansion surface layer places the underlying ceramic surface in compression on cooling, reducing width and depth of surface flaws. ${ }^{71}$ It should be noted that autoglazing does not result in such strengthening.

Crystalline reinforcement, by contrast, introduces higher crystalline content into the ceramic to enhance crack resistance. A higher thermal expansion crystalline phase embedded in a lower-expansion matrix material results in compressive stress at the crystal-matrix interface. Such stresses have been shown to deflect crack fronts and increase fracture resistance. ${ }^{72}$

Polycrystalline zirconia can be strengthened through stress-induced transformation. When stressed, these materials can undergo a phase change that is accompanied by a volumetric increase. When stress triggers the phase change, strengthening results from increased grain volume in the vicinity of the crack. ${ }^{73}$ The volumetric increase results in a compressed surface layer and reduces crack width. These materials are sometimes referred to as "self-healing" ceramics. It should be noted, however, that the original fracture remains present. At this time subsequent fracture resistance of such restorations has not been studied sufficiently to enable reliable prediction of clinical performance.

Stress corrosion is recognized as weakening ceramics in moist environments via a chemical reaction between water and the ceramic material that can result in a reduction in fracture strength by as much as $30 \% .{ }^{74}$ A number of authors have concluded that this impacts the clinical performance of dental ceramics. ${ }^{75,76}$ It should be noted that all contemporary luting agents permit some degree of moisture migration. Use of barriers that reduce moisture exposure of the internal 
surface of restorations, such as the metal foil on which Captek crowns are baked that remains part of the restoration when it is luted, may reduce fracture incidence through such reduction to moisture exposure. ${ }^{77}$

\section{Aesthetic considerations}

The clinical choice to select a material for restoration of a posterior tooth, whether amalgam, composite, gold, or ceramic, is influenced by multiple factors. If patients demand an "aesthetic" restoration, options are limited to composite or ceramic. When the most economical option is desired, the choice typically is between amalgam or composite. If the longest service record is sought, many dentists would respond with a gold restoration. In a survey of dentists' preferences for the restoration of their own molar teeth, it was found that most dentists did not replace traditional metallic restorations with aesthetic alternatives, and still chose nonaesthetic options for a significant number of their own restorations. ${ }^{78}$

Each material appears to have a niche, however, as newer and further-improved aesthetic material choices become available, such as the relatively recent introduction of the lithium disilicates. The exact place where ceramic inlays fit into the overall selection has continued to morph.

For aesthetic restorations, the question becomes, under what circumstances does a direct composite best fulfill the treatment needs, and when is an indirect ceramic inlay a more appropriate choice?

The versatility of layered porcelains permits the knowledgeable ceramist and clinician to mimic the chroma, shade, hue, translucency, and surface finish of natural teeth. Improvement of their aesthetic qualities and physical properties has served as a constant catalyst to the further development of aesthetic materials.

Newer low-fusing porcelains with firing temperatures around $760^{\circ} \mathrm{C}$ (compared to about $940^{\circ} \mathrm{C}$ for conventional porcelain) allow for improved opalescence qualities in enamel porcelain, while simultaneously improving porcelain polishability. ${ }^{14}$

Several authors report that patients were satisfied with the aesthetic results of both direct composites and ceramic inlays. ${ }^{79,80}$ However, one study reported lower color match scores for the ceramic inlays (85\%) than for the composite inlays $(100 \%)$ at baseline due to their monochromatic nature, and even lower scores after 3 years (58.8\% for ceramics and $86.5 \%$ for resin), ${ }^{79}$ while another study reported no significant difference in aesthetic scores after 10 years of clinical function. Thus, from a patient's perspective, if aesthetic differences are not a major factor, the question becomes why investment in the ceramic restoration might be preferable over a direct composite. The logical next consideration, then, is which material will provide the longest service to the patient. Stress distribution and bonding are significant factors contributing to restoration longevity.

\section{Stress distribution}

A number of studies have evaluated differences in stress distribution and flexure between ceramic and composite inlays. Finite-element modeling suggests that composite restored teeth exhibit increased coronal flexure, whereas ceramic inlays result in increased coronal rigidity. Compared to ceramics, composite with a low modulus of elasticity exhibits increased tension at the dentin-bonding agent junction, suggesting that porcelain inlays have a lower risk of debonding. ${ }^{80}$

In vitro studies suggest that ceramic inlays may perform better than composite resin inlays in terms of adaptation to dentin, marginal adaptation, and cusp stabilization. ${ }^{81-83}$ In vivo, ceramic inlays have been shown to exhibit superior restoration integrity and anatomic form. ${ }^{84}$

Logically, one might conclude that because of these advantages, the comparative long-term performance of the ceramic inlay should be superior. If so, less frequent need to replace the restoration would in fact result in improved longevity, making the ceramic inlay the more economical choice.

\section{Luting considerations}

The use of traditional acid-based reaction cements such as zinc phosphate and glass ionomer results in ceramic inlays that are more prone to fracture in comparison to an adhesively bonded ceramic inlay. ${ }^{85}$

The use of resin-modified glass ionomer luting agents gained some popularity in practice largely because of comparatively superior strength compared with traditional glass ionomer, and potential release of fluoride. The clinical significance of the latter is questionable, because the actual fluoride release is of fairly short duration, ${ }^{86}$ and the cohesive strength of resin-modified ionomers remains lower than for composite resins. ${ }^{87}$

At the resin-restoration interface, a low-viscosity adhesive resin can be used to achieve a strong micromechanical bond with the ceramic that has been etched with hydrofluoric acid. ${ }^{88}$ The use of silane coupling agents further enhances the bond: they improve wettability of the ceramic by the resin and the formation of chemical bonds. ${ }^{89}$ 
Bonding a ceramic inlay to etched enamel results in minimal microleakage, provided that proper technique is used. Etching of the ceramic with hydrofluoric acid followed by use of a silane coupling agent can have a strengthening effect on the resulting bond, depending on the specific material used. ${ }^{90}$

Clinically, luting-agent selection is a function of the ceramic material chosen to fabricate the restoration (Table 4). Inlays fabricated from silica-based ceramics, such as feldspathic porcelains, leucite-reinforced porcelains, or lithium disilicate glass ceramics, can be etched with hydrofluoric acid and silanated prior to cementation with a phosphatemodified resin luting agent. Resin luting agents have been shown to offer higher bond strengths than can be achieved with traditional glass-ionomer. ${ }^{91}$ Lithium disilicate glass ceramics, however, may also be cemented with traditional luting agents without internal surface treatment.

Inlays fabricated from dense-sintered $\mathrm{ZrO}$ (eg, Lava) or dense-sintered $\mathrm{AlO}$ (eg, ProCera) do not benefit from etching and can be cemented with traditional luting agents, such as zinc phosphate or glass ionomers. Alternatively, phosphatemodified resin cement may be used.

The use of dual-cured cements has been advocated for luting ceramic inlays because of the varied ceramic thickness through which light must pass in order to activate the polymerization reaction..$^{92}$ When using dual-cured resin cements, the ultimate hardness is a function of light exposure, and marked differences have been shown between various materials in terms of the ratio of chemical and light-activated catalysts. ${ }^{93}$ In a comparative in vitro study of five dual-cure cements, typical 40-second exposure time, as recommended by the manufacturer, was shown to be insufficient to compensate for light attenuation through a $4 \mathrm{~mm}$ thickness of porcelain. ${ }^{94}$ Dual-cure resin luting agents require visible light exposure to reduce risk of discoloration, and exposure time should be as long as possible, taking light attenuation into consideration as a function of restoration thickness. ${ }^{95}$ The durability of the resin bond is affected by the amount of light the luting agent is exposed to. ${ }^{96} \mathrm{All}$ of the above relate to the degree of conversion of the cured resin matrix. The microhardness of the cured resin is believed to be a reasonable measurement of the degree of conversion, as polymer properties depend on cross-linking density ${ }^{97}$ Ceramic inlays are superior to composite resin inlays in terms of light transmission, ${ }^{98}$ which aids achieving a higher degree of conversion.

\section{Recommended bonding procedures}

When bonding a ceramic inlay, proper isolation is imperative. Use of a rubber dam is highly recommended, but may not always prove practical. The preparation is cleaned with pumice, rinsed, and dried. The internal surface of the restoration is then etched with hydrofluoric acid, after which it is again rinsed and dried. A silane coupling agent is applied on the etched surfaces and allowed to air dry. Recommendations for the time of silane application vary from 30 seconds to 2 minutes. The chemistry of each system will vary; therefore, following the manufacturer's directions and not mixing products is advisable. ${ }^{99,100}$

The use of Teflon tape interproximally is a convenient way to protect adjacent teeth. Alternatively, a soft-metal matrix can be used. The preparation is prepared as recommended by the manufacturer, with the proper etch, prime, and bond. Resin luting agent is then applied to the inlay or the preparation. The inlay is seated and excess luting material

Table 4 Luting recommendations

\begin{tabular}{|c|c|c|c|}
\hline Inlay material & $\begin{array}{l}\text { Recommended surface } \\
\text { treatment }\end{array}$ & Coupling agent & $\begin{array}{l}\text { Recommended luting } \\
\text { agent(s) }\end{array}$ \\
\hline Feldspathic porcelain & Hydrofluoric acid etch & Silane coupling agent & Compomers, composite resin \\
\hline Leucite reinforced porcelain & Hydrofluoric acid etch & Silane coupling agent & Compomers, composite resin \\
\hline Aluminous porcelain & Hydrofluoric acid etch & Silane coupling agent & Compomers, composite resin \\
\hline Lithiumdisilicate glass-ceramics & Hydrofluoric acid etch & Silane coupling agent & Compomers, composite resin \\
\hline Dense sintered $\mathrm{ZrO}_{2}$ & NA or metal/Zr primer & NA & $\begin{array}{l}\text { Zinc phosphate, zinc polycarboxylate, glass } \\
\text { ionomer or phosphate modified resin }\end{array}$ \\
\hline Dense sintered $\mathrm{Al}_{2} \mathrm{O}_{3}$ & NA & NA & $\begin{array}{l}\text { Zinc phosphate, zinc polycarboxylate, glass } \\
\text { ionomer or phosphate modified resin }\end{array}$ \\
\hline Dense sintered AIO & Air abrasion & NA & Phosphate modified resin \\
\hline Glass infiltrated zirconia & NA & NA & Phosphate modified resin \\
\hline Glass infiltrated alumina & NA & NA & Phosphate modified resin \\
\hline Glass infiltrated alumina & Air abrasion & NA & $\begin{array}{l}\text { Zinc phosphate, zinc polycarboxylate, glass } \\
\text { ionomer }\end{array}$ \\
\hline
\end{tabular}

Adapted with permission from Seghi RR. Relationship between Luting Agents and Ceramics. Data presented at the Boucher Conference. Columbus, OH, USA. 2010. Abbreviations: $\mathrm{NA}$, not applicable; $\mathrm{ZrO}_{2}$, Zirconium oxide; $\mathrm{Al}_{2} \mathrm{O}_{3}$, Aluminum oxide. 
is removed. The restoration should be supported while the resin is cured. Gross excess resin can be removed after a spot cure, prior to completely curing the resin, but care must be taken not to cause inadvertent deficiencies at the tooth-restoration interface. Light curing is then done in accordance with the resin manufacturer's recommendations. Any residual flash can be removed with a scalpel or suitable curette, after which the occlusion is evaluated and adjusted as necessary. Any adjusted surfaces can be polished with a suitable polishing system, such as diamond polishing paste or rubber points.

\section{Longevity}

When evaluating the longevity of any dental restoration, it is prudent to analyze the technological advancements that occur throughout the evaluation period. For ceramic inlays in particular, the rapid evolution of the available materials, methods, and associated technologies make this a challenge. Over the course of the last decade, significant improvements have been developed in ceramics, bonding, and technology used in the manufacturing process. ${ }^{101}$

A number of variables are unpredictable and uncontrollable: the quality of tooth structure the restoration is bonded to, the applied load, and oral hygiene; all impact clinical longevity. Among the variables the clinician can control are tooth-preparation design, the type of restorative material selected, and the bonding technique used.

It has been reported that ceramics appear to have similar short-term survival rates to other materials on posterior teeth. ${ }^{102}$ A 2003 study in which ceramic inlay longevity was compared to that of other posterior restorations concluded that no strong evidence base existed to support any performance difference, reporting an 11\% failure rate after 5 years. ${ }^{103}$ One retrospective study evaluated 141 two-surface inlays and 155 three-surface inlays with a mean observation period of almost 9 years, and reported a 12-year inlay survival of $89.6 \%$, with increased failure rates in nonvital teeth. The author concluded that ceramic inlays are a viable restoration for posterior teeth, but do not provide comparable longevity to the posterior cast-gold inlays. ${ }^{104}$ In contrast, CEREC inlays have been reported to have $89 \%$ survival at 10 years, with clinical failure rates being comparable to those of cast gold. ${ }^{105}$

Porcelain fracture has been reported as a primary reason for restoration failure. ${ }^{106,107}$ Therefore, it appears prudent to avoid excessive loading of porcelain inlays. Over an 11.5 year observation period of 183 inlays, porcelain inlay survival rate for premolars was $99 \%$ in comparison to $95 \%$ for molars. ${ }^{108}$
In this study, all preparation margins had been placed in enamel, and the prepared teeth were isolated under rubber dam during the luting procedure.

In 2003, Hayashi et al published a review evaluating prospective clinical trials of ceramic inlays reported from 1990 to $2001 .^{109}$ Following his research, Pol and Kalk published a subsequent systematic review in which the literature from 2001 to 2009 was assessed on the same subject matter. ${ }^{79}$ In regard to longevity of ceramic inlays, both reviews concluded no difference between ceramic and other materials in the first postoperative year. ${ }^{79,109}$ Several clinical trials have demonstrated promising survival rates of greater longevity. A 10-year prospective study on IPS Empress inlays gave a survival probability of $80 \%-95 \% .{ }^{110}$ Another 8 -year study reported a $92 \%$ survival rate with the same material. ${ }^{111}$ Yet another study that observed 187 ceramic inlays and onlays over a 10 -year period found a survival probability rate of $90.4 \%$. ${ }^{112}$ This study evaluated restorations fabricated with the earliest version of chair-side CAD/CAM - the CEREC-1. Since then, the acquisition units, software, milling units, and ceramic materials used have advanced significantly. In a later study in which the CEREC-3 was used, partial ceramic crowns demonstrated survival rates reportedly similar to those of cast-gold partial crowns. ${ }^{113}$

In one study, all-ceramic restorations, including crowns, veneers, inlays, and onlays, were reported to have an estimated survival probability of $93.5 \%$ over 10 years. ${ }^{48}$ When reviewing these reports, many of which are retrospective analyses, it is not possible to identify a specific survival time after which failure is likely to occur. However, as one reviews this part of the literature, a gradual consensus emerges that under average functional conditions, bonded porcelain inlays with preparation margins located on enamel can reasonably be expected to provide approximately 8-10 years of service. Under favorable conditions, longer service may well be realized. Although such is a noticeably shorter serviceable life span than is routinely achieved by its less aesthetic counterparts, the aesthetic advantage of the ceramic inlay can provide patient satisfaction that cannot be routinely achieved with conventional metal restorations.

\section{Summary}

When a posterior tooth is compromised, eg, because of wide isthmus preparations, ceramic inlays offer advantages over direct composite resin restorations. They offer an aesthetic long-lasting alternative with a predictable degree of clinical success. The physical properties of ceramics have improved dramatically in recent years, and with improvements in 
CAD/CAM technologies, internal and marginal adaptation of milled restorations continues to improve. Due to the inherently brittle nature of ceramic materials, adequate tooth reduction is necessary to provide sufficient bulk for the ceramic to withstand functional loads. Preparation margins should ideally be located in enamel, which will result in a strong and durable bond when resin luting agents are used. By comparison, resin bonding to margins located on dentin exhibits greater potential for microleakage.

Ceramic inlay luting procedures require excellent isolation, etching of the ceramic, the use of a silane coupling agent, and etching of the prepared tooth. A careful technique will ensure delivery of a predictable, long-lasting, aesthetic ceramic inlay restoration.

\section{Disclosure}

The authors report no conflicts of interest in this work.

\section{References}

1. Neme AL, Evans DB, Maxson BB. Evaluation of dental adhesive systems with amalgam and resin composite restorations: comparison of microleakage and bond strength results. Oper Dent. 2000;25(6):512-519.

2. Bonsor SJ. Bonded amalgams and their use in clinical practice. Dent Update. 2011;38(4):222-230.

3. Chin G, Chong J, Kluczewska A, Lau A, Gorjy S, Tennant M. The environmental effects of dental amalgam. Aust Dent J. 2000;45(4): 246-249.

4. Rowe NH, Sidhu KS, Chadzynski L, Babcock RF. Potential public health risks related to mercury/amalgam discharge from dental offices. J Mich Dent Assoc. 1996;78(2):32-36.

5. Shraim A, Alsuhaimi A, Al-Thakafy JT. Dental clinics: a point pollution source, not only of mercury but also of other amalgam constituents. Chemosphere. 2011;84(8):1133-1139.

6. Jackson R. Esthetic inlays and onlays. In: Freedman G. Contemporary Esthetic Dentistry. St Louis: Elsevier; 2012:469-481.

7. Ring ME. Dentistry: An Illustrated History. New York: Mosby; 1985.

8. Ernsmere JB. Porcelain dental work. Br J Dent Sci. 1900;43:547.

9. Peck AE. A System of Porcelain Inlays: A method for building anterior contour and occlusal fillings. Dent Summ. 1904;24(3):179-183.

10. Lamstein A, Blechman H. Marginal seepage around acrylic resin veneers in gold crowns. J Prosthet Dent. 1956;6(5):706-709.

11. Weinstein M, Weinstein AB, inventor. Fused porcelain-to-metal teeth. United States patent 3052982. September 11, 1962.

12. McLean JW, Hughes TH. The reinforcement of dental porcelain with ceramic oxides. Br Dent J. 1965;119(6):251-267.

13. Southan DE. Dental porcelain. In: von Fraunhofer JA, editor. Scientific Aspects of Dental Materials. London: Buttersworths; 1975:277-279.

14. Leinfelder K. Porcelain esthetics for the 21 st century. JAm Dent Assoc. 2000;131 Suppl:47S-51S.

15. McLaren E. CAD/CAM dental technology. Compend Contin Educ Dent. 2011;32(4):73-82.

16. Mörmann WH, Brandestini M, Lutz F. The CEREC system: computerassisted preparation of direct ceramic inlays in 1 setting. Quintessenz. 1987;38(3):457-470. German.

17. Mörmann WH, Brandestini M. CEREC system: computerized inlays, onlays and shell veneers. Zahnartzl Mitt. 1987;77(21):2400-2405. German.

18. Mörmann WH. The evolution of the CEREC system. JAm Dent Assoc. 2006;137 Suppl:7S-13S.
19. Simonsen RJ, Calamia JR. Tensile bond strength of etched porcelain. J Dent Res. 1983;27:671-684.

20. Adair PJ, Bell B, Pameijer CH. Casting technique of machinable glass ceramics [abstract]. J Dent Res. 1980;59:475.

21. Pameijer CH, Grossman D, Adair PJ. Physical properties of a castable ceramic dental restorative material [abstract]. J Dent Res. 1980;59: 474.

22. Sozio RB, Riley EJ. The shrink-free ceramic crown. J Prosthet Dent. 1983;49(2):182-187.

23. Dong JK, Luthy H, Wohlwend A, Schärer P. Heat-pressed ceramics: technology and strength. Int J Prosthodont. 1992;5(1):9-16.

24. Denry IL. Recent advances in ceramics for dentistry. Crit Rev Oral Biol Med. 1996;7(2):134-143.

25. Cramer NB, Stansbury JW, Bowman CN. Recent advances and developments in composite dental restorative materials. J Dent Res. 2011;90(4):402-416.

26. Rosenstiel SF, Land MF, Fujimoto J. Contemporary Fixed Prosthodontics, 4th ed. St Louis: Elsevier; 2006. Page 327.

27. Land MF. Wear Testing of Human Tooth Enamel Versus Different Types of Dental Porcelain of Varying Surface Finish [master's thesis]. Indianapolis: Indiana University; 1978.

28. Kadowaka A, Suzuki S, Tanaka T. Wear evaluation of porcelain opposing gold, composite resin, and enamel. J Prosthet Dent. 2006;96(4): 258-265.

29. Al-Malik MA. An Investigation of the Dynamic Mechanical Properties of Dental Root Form Implants [master's thesis]. Birmingham (AL): University of Alabama School of Dentistry; 1991.

30. Leinfelder KF, Beaudreau RW, Mazer RB. An in vitro device for predicting clinical wear. Quintessence Int. 1989;20(10):755-761.

31. Christensen R. Low-fusing porcelain-metal crowns. Clin Res Assoc Newsl. 1999;23(2):1-2.

32. Clelland NL, Agarwala V, Knobloch LA, Seghi RR. Relative wear of enamel opposing low-fusing dental porcelain. J Prosthodont. 2003;12(3):168-175.

33. Larsen-Basse J. Abrasive wear of ceramics. In: Jahanmir S, editor. Friction and Wear of Ceramics. New York: Marcel Dekker; 1994: 99-115.

34. Seghi RR, Rosenstiel SF, Bauer P. Abrasion of human enamel by different dental ceramics in vitro. J Dent Res. 1991;70(3):221-225.

35. Reeves N, Gore K, Meiers JC. Enamel wear against In-Ceram and Vitadur-N with various finishes [abstract]. J Dent Res. 1993;72: 187.

36. Giordano R, Cima M, Pober R. Effects of surface finish on flexural strength of various dental ceramics. Int J Prosthodont. 1995;8(4): 311-319.

37. Fairhurst CW, Lockwood PE, Ringle RD, Thompson WO. The effect of glaze on porcelain strength. Dent Mater. 1992;8(3):203-207.

38. Ward MT, Tate WH, Powers JM. Surface roughness of opalescent porcelains after polishing. Oper Dent. 1995;20(3):106-110.

39. Monaco C, Cardelli P, Bolognesi M, Scotti R, Ozcan M. Inlay-retained zirconia fixed dental prosthesis: clinical and laboratory procedures. Eur $J$ Esthet Dent. 2012;7(1):48-60.

40. Wolfart S, Kern M. A new design for all-ceramic inlay-retained fixed partial dentures: a report of 2 cases. Quintessence Int. 2006;37(1): $27-33$.

41. Ohlmann B, Rammelsberg P, Schmitter M, Schwarz S, Gabbert O. Allceramic inlay-retained fixed partial dentures: preliminary results from a clinical study. J Dent. 2008;36(9):692-696.

42. Thompson MC, Field CJ, Swain MV. The all-ceramic, inlay supported fixed partial denture. Part 2. Fixed partial denture design: a finite element analysis. Aust Dent J. 2011;56(3):302-311.

43. Thompson MC, Field CJ, Swain MV. The all-ceramic, inlay supported fixed partial denture. Part 3. Experimental approach for validating the finite element analysis. Aust Dent J. 2012;57(1):23-30.

44. White SN, Miklus VG, McLaren EA, Lang LA, Caputo AA. Flexural strength of a layered zirconia and porcelain dental all-ceramic system. J Prosthet Dent. 2005;94(2):125-131. 
45. Bergman M. The clinical performance of ceramic inlays: a review. Aust Dent J. 1999;44(3):157-168.

46. Yang S, Cook N, Paddock C. All-ceramic inlays and onlays. Clin Update. 2005;27(2):1-2.

47. Heymann H, Swift E, Ritter A. Sturdevant's Art and Science of Operative Dentistry, 6th ed. St Louis: Elsevier; 2013. Page 287.

48. Beier U, Kapferer I, Dumfahrt H. Clinical long-term evaluation and failure characteristics of 1,335 all-ceramic restorations. Int J Prosthodont. 2012;25:70-78.

49. Gibbs CH, Mahan PE, Mauderli A, Lundeen HC, Walsh EK. Limits of human bite strength. J Prosthet Dent. 1986;56(2):226-229.

50. Moscovich H, Roeters FJ, Verdonschot N, de Kanter RJ, Creugers NH. Effect of composite basing on the resistance to bulk fracture of industrial porcelain inlays. J Dent. 1998;26(2):183-189.

51. Scherrer SS, de Rijk WG. The fracture resistance of all-ceramic crowns on supporting structures with different elastic moduli. Int J Prosthodont. 1993;6(5):462-467.

52. Giordano R. Materials for chairside $\mathrm{CAD} / \mathrm{CAM}$ produced restorations. J Am Dent Assoc. 2006;137 Suppl 1:14S-21S.

53. Hayashi M, Miura M, Nishimura N, Takeshige F, Edisu S. Effects of cavity form and setting expansion of refractory dies on adaptability of fired ceramic inlays. Oper Dent. 2000;25(1):33-39.

54. Arnetzl GV, Arnetzl G. Design of preparations for all-ceramic inlay materials. Int J Comput Dent. 2006;9(4):289-298.

55. Berry TG, Osborne JW. Dentin bonding vs enamel bonding of composite restorations: a clinical evaluation. Dent Mater. 1989;5(2):90-92.

56. Pröbster L, Diehl J. Slip-casting alumina ceramics for crown and bridge restorations. Quintessence Int. 1992;23(1):25-31.

57. Sulaiman F, Chai J, Jameson LM, Wozniak WT. A comparison of the marginal fit of In-Ceram, IPS Empress, and Procera crowns. Int $J$ Prosthodont. 1997;10(5):478-484.

58. Pera P, Gilodi S, Bassi F, Carossa S. In vitro marginal adaptation of alumina porcelain ceramic crowns. J Prosthet Dent. 1994;72(6): $585-590$.

59. Shearer B, Gough M, Setchell D. Influence of marginal configuration and porcelain addition on the fit of In-Ceram crowns. Biomaterials. 1996;17(19):1891-1895.

60. Molin M, Karlsson S. The fit of gold inlays and three ceramic systems. A clinical and in vitro study. Acta Odontol Scand. 1993;51(4):201-206.

61. Martin N, Jedynakiewicz NM. Interface dimensions of CEREC-2 MOD inlays. Dent Mater. 2000;16(1):68-74.

62. Addi A, Hedayati-Khams A, Poya A, Sjögren G. Interface gap size of manually and $\mathrm{CAD} / \mathrm{CAM}$-manufactured ceramic inlays/onlays in vitro. J Dent. 2002;30(1):53-58.

63. Mota CS, Demarco FF, Camacho GB, Powers JM. Microleakage in ceramic inlays luted with different resin cements. J Adhes Dent. 2003;5(1):63-70.

64. Uludag B, Ozturk O, Ozturk AN. Microleakage of ceramic inlays luted with different resin cements and dentin adhesives. $J$ Prosthet Dent. 2009;102(4):235-224.

65. Hahn P, Attin T, Gröfke M, Hellwig E. Influence of resin cement viscosity on microleakage of ceramic inlays. Dent Mater. 2001;17(3): 191-196.

66. Rosenstiel SF, Land MF, Fujimoto J. Contemporary Fixed Prosthodontics, 4th ed. St Louis: Elsevier: 2006.

67. McCabe JF, Walls AWG. Applied Dental Materials, 9th ed. Oxford: Blackwell; 2008;89-91.

68. Mackert JR Jr, Williams AL. Microcracks in dental porcelain and their behavior during multiple firing. J Dent Res. 1996;75(7):1484-1490.

69. Kelly JR. Ceramics in restorative and prosthetic dentistry. Annu Rev Mater Sci. 1997;27:443-468.

70. Seghi RR, Crispin BC, Mito W. The effect of ion-exchange strengthening of feldspathic dental porcelains. Int J Prosthodont. 1990;3(2): 130-134.

71. Denry IL, Holloway JA, Tarr LA. Effect of heat treatment on microcrack healing behavior of a machineable dental ceramic. J Biomed Mater Res. 1999;48(6):791-796.
72. Mackert JR Jr, Rueggeberg EA, Lockwood PE, Evans AL, Thompson WO. Isothermal anneal effect on microcrack density around leucite particles in dental porcelain. J Dent Res. 1994;73(6):1221-1227.

73. Garvic RC, Hannink RH, Pascoe RT. Ceramic steel? Nature. 1975;258(5537):703-704.

74. Sherryl CA, O'Brien WJ. Transverse strength of aluminous and feldspathic porcelain. J Dent Res. 1974;53(3):683-690.

75. Rosenstiel SF, Denry IL, Zhu W, Gupta PK, van der Sluys RA. Fluoralkylethyl silane coating as a moisture barrier for dental ceramics. J Biomed Mater Res. 1993;27(3):415-417.

76. Morena R, Beaudreau GM, Lockwood PE, Evans AL, Fairhurst CW. Fatigue of dental ceramics in a simulated oral environment. J Dent Res. 1986;65(7):993-997.

77. Kelly JR, Giordano R, Pober R, Cima MJ. Fracture surface analysis of dental ceramics: clinically failed restorations. Int $J$ Prosthodont. 1990;3(5):430-440.

78. Rosenstiel SF, Land MF, Rashid RG. Dentists' molar restoration choices and longevity: a web-based survey. J Prosthet Dent. 2004;91(4): 363-367.

79. Pol CW, Kalk W. A systematic review of ceramic inlays in posterior teeth: an update. Int J Prosthodont. 2011;24(6):566-575.

80. Thordrup M, Isidor F, Hörsted-Bindsler P. A prospective clinical study of indirect and direct composite and ceramic inlays: ten-year results. Quintessence Int. 2006;37(2):139-144.

81. Mehl A, Kunzelmann KH, Folwaczny M, Hickel R. Stabilization effects of CAD/CAM ceramic restorations in extended MOD cavities. JAdhes Dent. 2004;6(3):239-245.

82. Manhart J, Schmidt M, Chen HY, Kunzelmann KH, Hickel R. Marginal qualities of tooth-colored restorations in class II cavities after artificial aging. Oper Dent. 2001;26(4):357-366.

83. Dietschi D, Moor L. Evaluation of the marginal and internal adaptation of different ceramic and composite inlay systems after an in vitro fatigue test. J Adhes Dent. 1999;1(1):41-56.

84. Manhart J, Chen HY, Neuerer P, Scheibenbogen-Fuchsrunner A, Hickel R. Three-year clinical evaluation of composite and ceramic inlays. Am J Dent. 2001;14(2):95-99.

85. Filho AM, Vieira LCC, Araujo E, Baratieri LN. Ceramic inlays and onlays: clinical procedures for predictable results. J Esthet Restor Dent. 2003;15(6):338-351.

86. Friedl KH, Schmalz G, Miller KA, Shams M. Resin-modified glass ionomer cements: fluoride release and influence on Streptococcus mutans growth. Eur J Oral Sci. 1997;105(1):81-85.

87. Van Dijken JWV, Örmin A, Olofsson AL. Clinical performance of pressed inlays luted with resin-modified glass ionomer and autopolymerizing resin composite cements. J Prosthet Dent. 1999;82(5): 529-535.

88. Stangel I, Nathanson D, Hsu CS. Shear strength of the composite bond to etched porcelain. J Dent Res. 1978;66(9):1460-1465.

89. Söderholm KJM, Shang SW. Molecular orientation of silane at the surface of colloidal silica. J Dent Res. 1993;72(6):1050-1054.

90. Blatz MB, Sadan A, Kern M. Resin-ceramic bonding: a review of the literature. J Prosthet Dent. 2003;89(3):268-274.

91. Pallesen U, van Dijken JWV. An 8-year evaluation of sintered ceramic and glass ceramic inlays processed by the CEREC CAD/CAM system. Eur J Oral Sci. 2000;108(3):239-246.

92. Nathanson D. Etched porcelain restorations for improved esthetics, part II: onlays. Compendium. 1987;8(2):105-110.

93. Hasegawa EA, Boyer DB, Chan DCN. Hardening of dual-cured cements under composite resin inlays. J Prosthet Dent. 1991;66(2): 187-192.

94. Lee IB, Um CM. Thermal analysis on the cure speed of dual cured resin cements under porcelain inlays. J Oral Rehabil. 2001;28(2):186-197.

95. Koishi Y, Tanoue N, Atsuta M, Matsumura H. Influence of visible-light exposure on color stability of current dual-curable luting composites. J Oral Rehab. 2002;29(4):387-393.

96. Foxton RM, Pereira PN, Nakajima M, Tagami J, Miura H. Durability of the dual-cure resin cement/silicon oxide ceramic bond with different curing strategies. J Adhes Dent. 2002;4(1):49-59. 
97. Shimura R, Nikaido T, Yamauti M, Ikeda M, Tagami J. Influence of curing method and storage condition on microhardness of dual-cure resin cements. Dent Mater J. 2005;24(1):70-75.

98. El-Badrawy WA, El-Mowafy OM. Chemical versus dual curing of resin inlay cements. J Prosthet Dent. 1995;73(6):515-524.

99. Alex G. Preparing porcelain surfaces for optimal bonding. Compend Contin Educ Dent. 2008;29(6):2-14.

100. Matinlinna JP, Lassila LVJ, Vallittu PK. Evaluation of five dental silanes on bonding a luting cement onto silica-coated titanium. J Dent. 2006;9(34):721-726.

101. Swift E, Sturdevant J, Soushell L. Indirect tooth colored restorations. In: Heymann H, Swift E, Ritter A. Sturdevant's Art and Science of Operative Dentistry, 6th ed. St Louis: Elsevier; 2013:280-295.

102. Chritchlow S. Ceramic materials have similar short term survival rates to other materials on posterior teeth. Evid Based Dent. 2012; 13(2):49.

103. Hayashi M, Yeung CA. Ceramic inlays for restoring posterior teeth. Cochrane Database Syst Rev. 2003;1:CD003450.

104. Beier US, Kapferer I, Bustscher D, Giesinger JM, Dumfahrt H. Clinical performance of all-ceramic inlay and onlay restorations in posterior teeth. Int J Prosthodont. 2012;25(4):395-402.

105. Sjögren G, Molin M, van Dijken J. A 10 year prospective evaluation of CAD/CAM-manufactured (CEREC) ceramic inlays cemented with a chemically cured or dual cured resin composite. Int J Prosthodont. 2004;17(2):241-246.
106. Hayashi M, Tsuchitani Y, Kawamura Y, Miura M, Takeshige F, Ebisu S. Eight-year clinical evaluation of fired ceramic inlays. Oper Dent. 2000;25(6):473-481.

107. van Dijken JW, Hasselrot L, Ormin A, Olofsson AL. Restorations with extensive dentin/enamel-bonded ceramic coverage. A 5 year follow-up. Eur J Oral Sci. 2001;109(4):222-229.

108. Fuzzi M, Rappelli G. Ceramic inlays: clinical assessment and survival rate. J Adhes Dent. 1999;1(1):71-79.

109. Hayashi M, Wilson NHF, Yeung CA, Worthington HV. Systematic review of ceramic inlays. Clin Oral Invest. 2003;7(1):8-19.

110. Stoll R, Cappel I, Jablonski-Momeni A, Pieper K, Stashniss V. Survival of inlays and partial crowns made of IPS empress after a 10-year observation period and in relation to various treatment parameters. Oper Dent. 2007;32(6):556-563.

111. Kramer N, Frankenberger R. Clinical performance of bonded leucitereinforced glass ceramic inlays and onlays after eight years. Dent Mater. 2005;21(3):262-271.

112. Otto T, De Nisco S. Computer-aided direct ceramic restorations: a 10-year prospective clinical study of CEREC CAD/CAM inlays and onlays. Int J Prosthodont. 2002;15(2):122-128.

113. Federlin M, Hiller K, Schmalz G. Controlled, prospective clinical split-mouth study of cast gold vs ceramic partial crowns: 5.5 year results. Am J Dent. 2010;23(3):162-167.
Clinical, Cosmetic and Investigational Dentistry

\section{Publish your work in this journal}

Clinical, Cosmetic and Investigational Dentistry is an international, peer-reviewed, open access, online journal focusing on the latest clinical and experimental research in dentistry with specific emphasis on cosmetic interventions. Innovative developments in dental materials, techniques and devices that improve outcomes and patient satisfac-

\section{Dovepress}

tion and preference will be highlighted. The manuscript management system is completely online and includes a very quick and fair peerreview system, which is all easy to use. Visit http://www.dovepress. com/testimonials.php to read real quotes from published authors. 